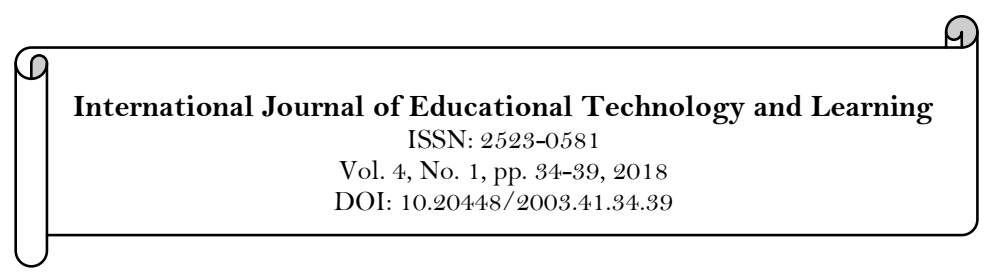

\title{
check for
updates \\ Evaluation of E-Learning Lessons for Strengthening Early Childhood Practitioner Use of Family Capacity-Building Practices
}

\author{
Dunst, C.J. ${ }^{2}$ \\ Howse, R.B. ${ }^{2}$ \\ Embler, D. ${ }^{3}$ \\ Hamby, D.W. ${ }^{4}$ \\ 1,2,3,4 Orelena Hawks Puckett Institute Asheville and Morganton, North Carolina, USA. \\ Email: cdunst@puckett.org
}

\begin{tabular}{|c|c|}
\hline Abstract & \\
\hline $\begin{array}{l}\text { Findings from a case study field-test evaluation of e-learning lessons } \\
\text { for promoting early childhood intervention practitioners } \\
\text { understanding and use of family capacity-building practices are } \\
\text { described. Participants were two early childhood program directors, } \\
\text { two early childhood technical assistance providers, and two early } \\
\text { childhood intervention practitioners. Pattern matching was used to } \\
\text { evaluate whether or not participants with different roles and } \\
\text { responsibilities judged the instructional design, interactivity, video } \\
\text { illustrations, and usefulness of the e-learning lessons similarly or } \\
\text { differently. Results indicated that the different features of the e- } \\
\text { learning lessons were rated highly by all but one participant and that } \\
\text { the patterns of responses were much the same regardless of } \\
\text { participants professional roles or responsibilities. Participant } \\
\text { feedback and suggestions were used to revise the e-learning lessons } \\
\text { and correct technical problems. }\end{array}$ & $\begin{array}{l}\text { Licensed: } \\
\text { This work is licensed under a } \\
\text { Creative Commons Attribution } \\
\text { 4.0 License. } \\
\text { Publisher: } \\
\text { Scientific Publishing Institute }\end{array}$ \\
\hline
\end{tabular}

\section{Introduction}

This brief report includes findings from an evaluation of e-learning lessons for promoting and strengthening early childhood intervention practitioners' understanding of and ability to use family capacitybuilding practices. Early childhood intervention includes the learning opportunities afforded infants, toddlers, and older preschoolers to promote the children's development (Dunst \& Espe-Sherwindt, 2017) and the procedures used to support parents' abilities to provide their children development-enhancing child learning opportunities (Dunst, 2006). Family capacity-building refers to practitioner use of evidence-based methods and strategies for supporting and strengthening parents' confidence and competence in providing their children with everyday learning opportunities (Swanson, Raab, \& Dunst, 2011).

Early childhood intervention that is based on parent-provided child learning opportunities necessitates that practitioners have the knowledge and skills to use family capacity-building practices (Kahn, Stemler, \& Berchin-Weiss, 2009; Mortensen \& Mastergeorge, 2014; Woods \& Brown, 2011). There is evidence, however, that many practitioners do not routinely use family capacity-building practices for any number of reasons (see e.g., (Dunst, Bruder, \& Espe-Sherwindt, 2014; Hebbeler \& Gerlach-Downie, 2002; McBride \& Peterson, 1997; Peterson, Luze, Eshbaugh, Jeon, \& Kantz, 2007). This was the basis for developing the e-learning lessons described next and evaluated by early childhood intervention practitioners knowledgeable about the key characteristics of family capacity-building practices.

\section{Family Capacity-Building Methods and Strategies}

Results from research syntheses of adult learning studies informed the development of the capacitybuilding methods and strategies used to design the e-learning lessons (Dunst \& Hamby, 2015; Dunst, Trivette, \& Hamby, 2010; Raab, Dunst, \& Trivette, 2013). The capacity-building strategies include (1) practitioner description of an intervention practice and the child outcomes or benefits of the practice, (2) 
practitioner demonstration of the use of the practice, (3) a parent's use of the intervention practice with his or her child, (4) practitioner supportive guidance and feedback to reinforce a parent's confidence and competence using the practice with his or her child, (5) practitioner-parent review of a parent's understanding of and experiences using the practice, and (6) practitioner-facilitated parent identification of the different ways in which the intervention practice can be used as part of everyday activities. The procedure has been found effective for promoting parents' use of a number of different early childhood intervention practices with their young children (Dunst, 2010; Dunst, Raab, \& Hamby, 2016; Swanson et al., 2011).

\subsection{Family Capacity-Building E-Learning Module and Lessons}

The e-learning module includes an introductory overview of the family capacity-building model, three lessons describing different sets of capacity-building methods and strategies, and a lesson including all six family capacity-building methods and strategies. The lessons are designed so that material learned in earlier lessons are the building blocks for material learned in later lessons. Table 1 outlines the content of the module and lessons. The e-learning lessons were developed specifically for practitioners (novice and beginners) with little or no prior training in or experience with parent-provided child learning activities and opportunities.

The introductory lesson includes an overview of the family capacity-building model and associated methods and strategies as well as the content of the four primary lessons. Lesson 1 includes illustrative examples of (1) practitioner descriptions of an intervention practice and (2) demonstrations of how to use a practice. Lesson 2 includes illustrative examples of different methods and strategies for (3) engaging a parent in using an intervention practice and (4) a practitioner providing supportive feedback and guidance.

Table-1. Focus of the lessons in the family capacity-building module.

\begin{tabular}{c|l}
\hline Lesson & Lesson Content \\
\hline Introduction & Overview of the family capacity-building methods and strategies \\
\hline 1 & $\begin{array}{l}\text { Practitioner introduction and illustration of the family capacity-building methods and } \\
\text { strategies }\end{array}$ \\
\hline 2 & $\begin{array}{l}\text { Practitioner methods and strategies for engaging a parent in the use of an intervention } \\
\text { practice and a practitioners' supportive feedback and guidance }\end{array}$ \\
\hline 3 & $\begin{array}{l}\text { Practitioner-facilitated parent review of his/her experience using an intervention } \\
\text { practice and parent identification of opportunities to use the practice }\end{array}$ \\
\hline 4 & Descriptions and illustrations of all six family capacity-building methods and strategies \\
\hline
\end{tabular}

Lesson 3 includes illustrative examples of (5) practitioner-facilitated parent review of his or her experience using a practice and (6) parent identification of opportunities to use the practice in everyday activities. The three lessons include extensive video footage of family capacity-building methods and strategies as well as include knowledge checks to reinforce a practitioner's understanding of the key characteristics of the family capacity-building methods and strategies.

Lesson 4 includes descriptions and illustrations of all six capacity-building methods and strategies and makes extensive use of video footage, knowledge checks, and interactive branching scenarios for reinforcing learner understanding and mastery of the capacity-building methods and strategies. The video examples, knowledge checks, and branching activities provide practitioners with multiple opportunities to see how the six strategies, taken together, include family capacity-building characteristics and consequences. This lesson also includes the complete description, illustration, and examples of family capacity-building to show how the different methods and strategies positively influence parenting confidence and competence.

The lessons are purposively formatted similarly because "applying organization to new learning causes learners to focus on the meaning of the lesson content" (Schwartz, 2014). The lessons are also intentionally designed to include deliberate and repetitive practice characteristics to facilitate deep understanding and the development of practitioner expertise (Alexander, 2003; Ericsson, Krampe, \& Tesch-Romer, 1993). The elearning lessons were prepared using Adobe Captivate 9 (Adobe Systems Incorporated, 2015) in order to include responsive content and interactive elements (video, knowledge checks, playback control, etc.). The instructional design includes multiple features and elements (roll-overs, embedded video, playback options, accessibility functions, etc.) to actively engage practitioners in learning to use the family capacity-building strategies. These various design features were used to create e-learning storyboarding lessons that allowed instructional content to be prepared in ways mirroring the key characteristics of adult learning methods and practices that are the foundations of the family capacity-building methods and strategies (Dunst, 2010; Raab et al., 2013).

\section{Purpose of the Evaluation}

The purpose of the evaluation described in this paper was to obtain experienced practitioners' feedback on the instructional design, interactivity, video illustrations, usefulness of the e-learning lessons, and content (family capacity-building model and strategies) of the e-learning lessons. A purposive sampling procedure was used to involve individuals who had different early childhood intervention roles and responsibilities but all of 
whom had knowledge and experience with the use of family capacity-building strategies. A quantitative case study methodology was used to determine if patterns of responses were the same or different for practitioners having different roles and responsibilities (Hak \& Dul, 2010).

\section{Method \\ 4.1. Participants}

The participants were two early childhood intervention program directors, two early childhood intervention technical assistance providers, and two early childhood intervention practitioners in six different programs all working in different states. The participants each had a master's degree or doctorate degree in early childhood education, early childhood special education, or a related field. They had an average of 13 years of experience working with young children and their families (Range $=5$ to $20+$ ).

\subsection{Procedure}

Participants were sent an email invitation describing the purpose and content of the e-learning lessons. The invitation included the five e-learning lessons and a link to a web-based feedback (evaluation) form. The invitation asked the participants to view the lessons, complete the interactive activities included in the lessons, and to then complete their evaluation of the lessons.

The feedback form included an item asking the participants to indicate the type of early childhood intervention practitioner who would benefit most from the lessons, seven Likert scale items for assessing various design features of the e-learning lessons, and an open-ended question asking for comments, feedback, and suggestions for improving the family capacity-building lessons.

The one question asking participants to "indicate which practitioners would benefit from using the capacity-building lessons" had five levels of expertise: Novice, beginner, experienced, seasoned, and expert. The item asked participants to "check all that apply" in terms of who would benefit the most from the lessons. The intended audiences for the e-learning lessons are novice and beginner-level practitioners and to a lesser extent experienced practitioners.

Yacovelli (2012) guidelines for evaluating e-learning were used to develop items to measure the instructional design, engagement properties of the lessons, ease of navigation, content sequencing, video examples of practitioner use of capacity-building strategies, level of interactivity, and the length of the lessons. Each item was rated on a 5-point scale (strongly disagree, disagree, neither agree nor disagree, agree, strongly agree) where participants were asked to indicate the extent to which they agreed with each item statement. Three of the Likert scale items assessed the instructional features of the lessons (design, navigation, and length), three items assessed the interactivity of the lessons (engaging, sequencing, and interactive activities), and one item assessed the video illustrations of the capacity-building strategies.

\subsection{Methods of Analysis}

The type of practitioner who would benefit most from the e-learning lessons was evaluated by computing (a) the number of participants who considered the lessons applicable to each of the five practitioner expertise levels and (b) determining if the pattern of responses matched the intended audiences for the lessons (Hak \& Dul, 2010; Yin, 2014). Regression analysis was used to confirm or disconfirm a linear decrease in the number of participants who considered the lessons of potential benefit to practitioners having different expertise levels (novice to expert levels of experience).

Patterns of responses to the instructional design, interactivity, and video illustration evaluative items were examined to determine if they were similar or different among the participants having different roles and responsibilities (program directors, technical assistance providers, and intervention practitioners) and whether there were differences in response patterns for the three different types of evaluative items (design, interactivity, and video illustrations). Both were determined using nonparametric statistical analysis procedures for analysis of data with small sample sizes (Siegel \& Castellan, 1988) and StatXact (Cytel Software Corporation StatXact, 2015).

\section{Results and Discussion \\ 5.1. Practitioner Expertise}

Figure 1 shows the number of participants who indicated that the e-learning lessons would be beneficial for promoting practitioner understanding and use of the family capacity-building methods and strategies. The pattern of responses matched the expected relationship between the level of practitioner expertise and a number of respondents who indicated that the family capacity-building lessons would be useful to different groups of practitioners. There was, as expected, a linear decrease in the number of participants who indicated that the lessons would benefit practitioners with different levels of expertise, $\beta=-.92, t=-3.93, d f=3, p=$ .029. The results indicated that field-test participants judged the e-learning lessons as most beneficial for practitioners with little or no experience working with families of young children. 


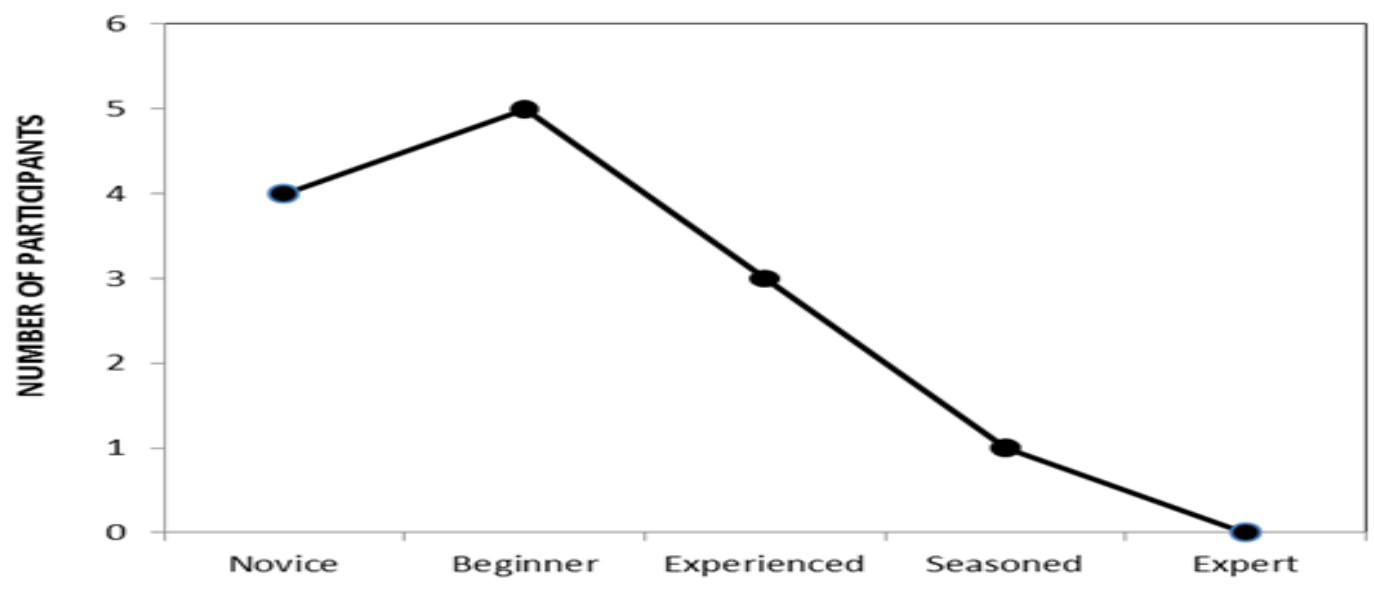

LEVEL OF PRACTITIONER EXPERTISE

Figure-1. Number of field-test participants attributing potential benefits of the e-learning lessons to practitioners with different degrees of practitioner expertise.

\subsection{Between Practitioner Comparisons}

The mean scores for the participants' ratings for the three e-learning lesson features are shown in Figure 2. Independent samples Kruskal-Wallis tests for between practitioner comparisons yielded no significant differences in the patterns of responses for the interactional design $\chi^{2}=4.19, d f=2, p=.123$, interactivity, $\chi^{2}$ $=0.25, d f=2, p=.882$, or video illustration, $\chi^{2}=1.25, d f=2, p=.535$, features of the e-learning lessons. The StatXact tests yielded a significant between-group difference for the instructional design, $\chi^{2}=10.50, d f=4, p$ $=.023$, but not for the interactivity, $\chi^{2}=0.45, d f=2, p=.411$, or the video illustration, $\chi^{2}=1.50, d f=2, p=$ .800 , features of the e-learning lessons. The pattern of results was much the same for the three groups of participants with the exception of several technical aspects of the e-learning lessons as described next.

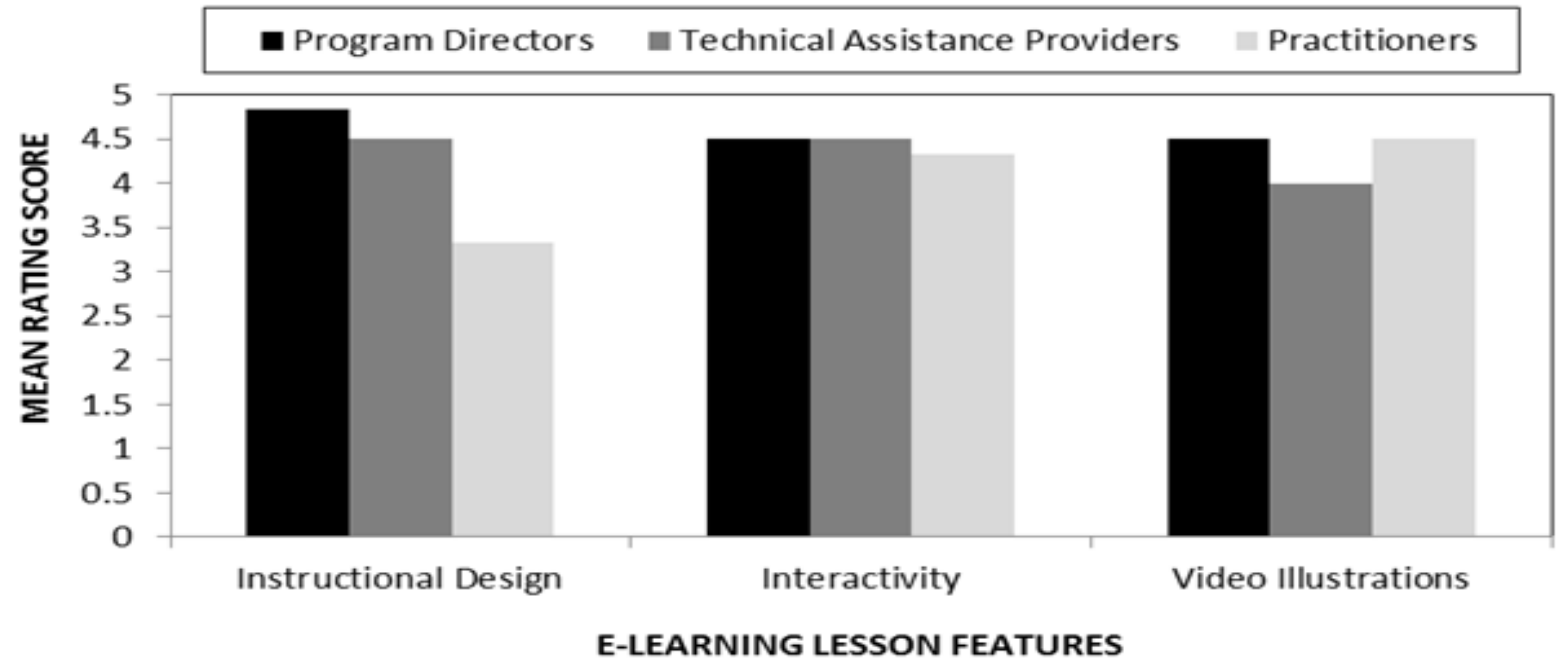

Figure-2. Field-test participants' average ratings for the three e-learning lesson features.

Close inspection of the participants' response to the seven Likert scale items found that both the program directors' and technical assistance providers' responses to the seven e-learning lesson features were rated either agree or strongly agree, whereas $86 \%$ of the responses of the early childhood practitioners to the seven items were rated the same. Two items (ease of navigation and length of the lessons) were rated as disagree by one practitioner, whereas the other practitioner rated these two items as well as the other five items as agree or strongly agree. The pattern of results, therefore, was more similar than different for 5 of the 6 participants.

\subsection{Between Lesson Feature Comparisons}

A Friedman's two-way analysis of variance test for the three e-learning lesson instructional features (design, interactivity, and video illustrations) was nonsignificant, $\chi^{2}=0.75, d f=2, p=.687$. The average scores for the three e-learning lesson features were $4.22(\mathrm{SD}=0.83)$ for the instructional design items, 4.45 $(\mathrm{SD}=0.27)$ for the interactivity items, and $4.33(\mathrm{SD}=0.52)$ for the video illustration item. The results showed that the pattern of responses was almost identical for the three e-learning lesson features, where the average scores reflected overall agreement on the seven evaluation items. 


\subsection{Open-Ended Responses}

The participants were asked to "provide any comments or suggestions for improving the family capacitybuilding lessons" where the responses were used to make changes and improvements to the e-learning lessons. Four of the six participants made extensive comments and suggestions whereas two participants provided only cursory feedback. All of the feedback related primarily to the technical aspects of the e-learning lessons.

The participants made many positive comments about the e-learning lessons although our main interest was feedback to improve the content of the lessons and the design features if so indicated. Most participants noted that there were problems with navigating various aspects of the e-learning lessons (video replay, next and back buttons, knowledge checks). One participant stated" There are some technical glitches in the lessons." All five lessons were reviewed, revised, and updated to correct all of the technical problems and glitches.

A related set of concerns had to do with video and audio not being in sync and the timing between lesson segments either overlapping or having extended pauses. These technical functions as well were corrected during the revision of the lessons.

\section{Conclusion}

Practitioners with different roles and responsibilities made very similar positive judgments about the different content and design features of the e-learning lessons. Results from the field-test evaluation proved informative for determining participants' judgments of the e-learning lessons and for identifying the particular (technical) features of the lessons that required corrections. Results also showed that a case study research design (Swanson, Roper, Raab, \& Dunst, 2006; Yin, 1994) highlighted similarities and differences in participants' evaluations of various features of the e-learning lessons.

\section{Acknowledgment}

The preparation of this paper was supported, in part, by funding from the U.S. Department of Education, Office of Special Education Programs (Grant \# H326P120002) awarded to the University of North CarolinaChapel Hill for the Early Childhood Technical Assistance Center. The opinions expressed, however, are those of the authors and no endorsement by either the funder or university should be inferred or implied.

\section{References}

Adobe Systems $\quad$ Incorporated. (2015). Adobe captivate $\quad 9 . \quad$ Retrieved https://www.bhphotovideo.com/bnh/controller/home? A=details $\& \mathrm{O}=\& \mathrm{Q}=\& \mathrm{ap}=\mathrm{y} \& \mathrm{c} 3 \mathrm{api}=1876 \% 2 \mathrm{C} \% 7 \mathrm{Bcreativ}$ e\%7D\%2C\%7Bkeyword\%7D\&gclid=EAIaIQobChMIleTx646q1QIVVjqBCh318A2-

EAQYAyABEgIfhfD_BwE\&is=REG\&m=Y\&sku= 1184869 .

Alexander, P. A. (2003). The development of expertise: The journey from acclimation to proficiency. Educational Researcher, 32(8), 10-14. Available at: 10.3102/0013189X032008010.

Cytel Software Corporation StatXact. (2015). Author: Cambridge, MA.

Dunst, C. J. (2006). Parent-mediated everyday child learning opportunities: I. Foundations and operationalization. CASE in Point, 2(2), 1-10.

Dunst, C. J. (2010). Family capacity-building in early childhood intervention: Effects on parent and child competence and confidence. Presentation made at the 8th National Congress on Early Intervention with Toung Children and their Families, Aveiro, Portugal.

Dunst, C. J., Bruder, M. B., \& Espe-Sherwindt, M. (2014). Family capacity-building in early childhood intervention: Do context and setting matter? School Community Journal, 24(1), 37-48.

Dunst, C. J., \& Espe-Sherwindt, M. (2017). Contemporary early intervention models, research, and practice for infants and toddlers with disabilities and delays. In J. M. Kauffman, D. P. Hallahan, E C. P. Pullen (Eds.), Handbook of special education (2nd ed.). New York: Routledge.

Dunst, C. J., \& Hamby, D. W. (2015). A case study approach to secondary reanalysis of a quantitative research synthesis of adult learning practices studies. International Journal of Learning, Teaching and Educational Research, 13(3), 181191.

Dunst, C. J., Raab, M., \& Hamby, D. W. (2016). Interest-based everyday child language learning. Foniatria y Audiologia, 36(4), 153-161. Available at: 10.1016/j.rlfa.2016.07.003.

Dunst, C. J., Trivette, C. M., \& Hamby, D. W. (2010). Meta-analysis of the effectiveness of four adult learning methods and strategies. International Journal of Continuing Education and Lifelong Learning, 3(1), 91-112.

Ericsson, K. A., Krampe, R. T., \& Tesch-Romer, C. (1993). The role of deliberate practice in the acquisition of expert performance. Psychological Review, $100(3), 363-406$.

Hak, T., \& Dul, J. (2010). Pattern matching. In A. J. Mills, G. Durepos, \& E. Wiebe (Eds.), Encyclopedia of case study research (pp. 664-666). Thousand Oaks: CA: Sage.

Hebbeler, K. M., \& Gerlach-Downie, S. G. (2002). Inside the black box of home visiting: A qualitative analysis of why intended outcomes were not achieved. Early Childhood Research Quarterly, 17(1), 28-51. Available at: 10.1016/So885-2006(02)00128-X.

Kahn, R., Stemler, S. E., \& Berchin-Weiss, J. (2009). Enhancing parent participation in early intervention through tools that support mediated learning. Journal of Cognitive Education and Psychology, 8(3), 269-287. Available at: 10.1891/1945-8959.8.3.269. 
McBride, S. L., \& Peterson, C. (1997). Home-based early intervention with families of children with disabilities: Who is doing what? Topics in Early Childhood Special Education, 17(2), 209-233. Available at: $10.1177 / 027112149701700206$.

Mortensen, J. A., \& Mastergeorge, A. M. (2014). A meta-analytic review of relationship-based interventions for lowincome families with infants and toddlers: Facilitating supportive parent-child interactions. Infant Mental Health Journal, 35(4), 336-353. Available at: 10.1002/imhj.21451.

Peterson, C. A., Luze, G. J., Eshbaugh, E. M., Jeon, H.-J., \& Kantz, K. R. (2007). Enhancing parent-child interactions through home visiting: Promising practice or unfulfilled promise? Journal of Early Intervention, 29(2), 119-140. Available at: $10.1177 / 105381510702900205$.

Raab, M., Dunst, C. J., \& Trivette, C. M. (2013). Adult learning procedure for promoting caregiver use of everyday child language learning practices. Everyday Child Language Learning Reports, 3, 1-9.

Schwartz, B. L. (2014). Memory: Foundations and applications (2nd ed.). Los Angeles: Sage.

Siegel, S., \& Castellan, N. J. J. (1988). Nonparametric statistics for the behavioral sciences (2nd ed.). New York: McGraw-Hill.

Swanson, J., Raab, M., \& Dunst, C. J. (2011). Strengthening family capacity to provide young children everyday natural learning opportunities. Journal of Early Childhood Research, 9(1), 66-80. Available at: $10.1177 / 1476718 X 10368588$.

Swanson, J., Roper, N., Raab, M., \& Dunst, C. J. (2006). Practitioner judgments of the usefulness of contextually mediated practices training activities. CASE in Point, 2(9), 1-7.

Woods, J., \& Brown, J. A. (2011). Integrating family capacity-building and child outcomes to support social communication development in young children with autism spectrum disorder. Topics in Language Disorders, 31(3), 235-246. Available at: 10.1097/TLD.obo13e318227fde4.

Yacovelli, S. (2012). Overcoming poopy e-learning: How to effectively evaluate "e. Los Gatos, CA: Smashbooks.

Yin, R. K. (1994). Discovering the future of the case study method in evaluation research. Evaluation Practice, 15(3), 283290.

Yin, R. K. (2014). Case study research: Design and methods (5th ed.). Thousand Oaks: CA: Sage. 